\title{
ASPECTOS DA REGULAÇÃO DE SANEAMENTO NO BRASIL
}

Jose Carlos Buzanello

Doutor em Direito. Professor do Curso de Mestrado em Direito da Universidade Federal do Estado do Rio de Janeiro UNIRIO) e Professor do Curso de Direito da Faculdade CNEC de Rio das Ostras.

\section{Resumo}

Analisa alguns aspectos da regulaçáo dos serviços de saneamento básico no Brasil, mais especificamente a política regulatória decorrente do processo de Reforma do Estado de 1995. Questiona os resultados de produtividade dos serviços de água e esgoto das concessionárias e o alcance dessas medidas para o consumidor-usuário.

\section{Palavras-chave}

Regulação de Saneamento Básico; Concessão de serviços de água e esgoto; Direitos do usuário de saneamento.

\section{Resumen}

Mira a algunos aspectos de la regulación de los servicios de saneamiento en Brasil, específicamente la política de regulación resultante del proceso de reforma del Estado de 1995. Cuestiona los resultados de la productividad de los servicios de agua y alcantarillado de los concesionarios y el alcance de estas medidas al consumismo usuario.

\section{Palabras clave}

Reglamento de Saneamiento Básico; Concesión de los servicios de agua y alcantarillado; Usuario saneamiento Derechos.

\section{Introdução}

Analisa esse artigo a situação tópica do saneamento básico (água e esgoto) no Brasil. O objeto que se apresenta é a discussão regulatória do setor de saneamento decorrente do processo de Reforma do Estado do Governo Henrique Cardoso, os fundamentos sobre a regulação no Brasil, bem como as características dos serviços de saneamento básico, aspectos relevantes da agencia reguladora, sem perder de vista, os direitos dos usuários. 
A importância dos serviços da água e esgoto é reconhecida universalmente como saúde preventiva, qualidade de vida e bem-estar. Também são significativos os efeitos ambientais de um sistema de saneamento que trate os esgotos de forma adequada. Os serviços de saneamento compreendem os serviços de abastecimento de água, esgotamento sanitário, drenagem urbana e resíduos sólidos, com repercussão nas áreas de meio ambiente, saúde pública e qualidade de vida.

O Brasil, em pleno século XXI, sétima economia do mundo, apresenta um grande déficit de atendimento dos serviços de saneamento, com forte desigualdade de atendimento por serviço prestado (água e esgoto), entre as regióes, e por origem de domicílio atendido (urbano e rural). O nível da cobertura de coleta de esgoto nas áreas urbanas no Brasil é dos piores dentre os países latino-americanos, alcançando apenas metade da população urbana. Até mesmo na região Sudeste, que é mais desenvolvida, o sistema urbano de esgoto cobre $70 \%$, menos que a Bolívia (72\%), a Colômbia (72\%) e o Peru $(80 \%)^{1}$. O governo federal aprovou em 2013 o Plano Nacional de Saneamento Básico (Plansab) um ambicioso plano de investimentos de mais de 500 bilhóes de reais para os próximos vinte anos (2014-2033), para resolver o problema do saneamento no Brasil. Esse esforço está cada vez mais distante de ser realizado em vista das rígidas restriçóes fiscais que começam em 2015.

No Brasil, o setor de saneamento está fortemente marcado pelo modelo institucional definido pelo Plano Nacional de Saneamento (Planasa), no início dos anos 1970, fundado na preponderância das companhias estaduais de saneamento, fundado no financiamento estatal da infra-estrutura e da regulação pelo financiamento. A crise começou com a crise fiscal inviabilizando o modelo de financiamento estatal e também pela "fragmentação de responsabilidades" dos entes federados estaduais e municipais na administração e na gestão do serviço de saneamento.

Após o esgotamento do modelo Planasa o que se segue é uma orientação pró-mercado, materializada no processo de privatização do Governo Fernando Henrique Cardoso e em reformas reguladoras que privilegiam a adoção de controles explícitos por meio de agências reguladoras setoriais. Decorrente da falência desse modelo houve a extinção dos seus programas de financiamento e a desregulamentação dos serviços, dando início ao aumento da participação privada no setor através de concessóes ao setor privado e da venda de parte das açôes de algumas companhias estaduais.

A idéia por trás dessa orientação pró-mercado é a de que privatização reduziria o déficit por não pressionarem mais o Estado por aportes de recursos públicos. A justificativa desse modelo privatista estava associada aos ganhos de escala provenientes da forma de

1 Os indicadores de saneamento variam conforme os órgãos técnicos, as metodologias empregadas nas pesquisas e os insumos de cobertura. Adotamos uma aproximaçáo de dados estatísticos. 
organização dos serviços e à viabilização do subsídio cruzado como forma de garantir o acesso dos pequenos municípios e da população de baixa renda aos serviços.

Surgem, então, por meio de privatização, as primeiras iniciativas de participação privada no setor de saneamento com o objetivo de reorganizar o setor, venda de controle acionário, concessão e outorga, contrato de administraçáo ou gestão, concessóes plenas, concessóes parciais. Por estes motivos, tornava-se imprescindível a execução de obras e serviços de ampliação e operação dos sistemas de água potável e de esgotamento sanitário, para os quais os Poderes Públicos não dispunham dos recursos necessários para investimentos.

Nessa nova modelagem surgem as primeiras concessóes dos serviços de água e esgoto a operadores privados em São Carlos (SP) em 1994, inclusive antes da promulgação da nova Lei de Concessóes (1995) e dez anos após já havia quarenta municípios brasileiros com o saneamento concedido a operadores privados. O setor de saneamento da Região dos Lagos no Estado do Rio de Janeiro entra nesse processo de privatizaçáo a partir de 1995, fundado em fatos reais e crônicos de má gestão de saneamento básico ofertado pela concessionária CEDAE, principalmente os Municípios de Araruama, Búzios, Cabo Frio e Rio das Ostras. Com a progressiva perda da capacidade do Estado do Rio de Janeiro e da concessionária CEDAE em alocar recursos na expansão e manutenção da infra-estrutura, ocasionou uma crescente deterioração da qualidade do saneamento com impactos indesejáveis na saúde publica e na produtividade econômica. As deficiências, tanto de regularidade do abastecimento de água potável, como de esgotamento sanitário, agravados pela existência de uma significativa população flutuante de turistas, emperravam o desenvolvimento turístico, prejudicando seus habitantes bem como a economia regional.

Agora, passado vinte anos, questiona-se qual o impacto inicial dessas mudanças e qual o quadro que se apresenta quanto à qualidade e quantidade dos serviços? Essas são as questóes centrais dessa pesquisa, principalmente a qualidade da regulação e da produtividade dos serviços de saneamento básico e o direito do consumidor-usuário.

\section{Política Regulatória}

Há vários modelos de regulatórios, mas quase todos possuem como objetivos a busca da eficiência do setor regulado e da eqüidade na prestação dos serviços públicos. Entretanto, os instrumentos regulatórios utilizados nem sempre são compatíveis com o alcance simultâneo de metas de eficiência e de eqüidade pretendidos. A regulação do setor de saneamento deve ser mais focada na prevenção e monitoramento das condutas das empresas, com as agências governamentais intervindo apenas quando necessário, fixando metas e resultados e respectivo cronograma de obras e serviços. 
Há muitas divergências de entendimento, tanto que Mario Possas recomenda que o “aparato regulatório seja flexível em termos de objetivos (incluindo metas) e instrumentos e que haja uma maior integração entre as atividades dos diferentes órgãos responsáveis pela regulação (tanto de defesa da concorrência como da regulação "ativa”) e um esforço deliberado e sistemático de troca de experiências e de aprendizado recíproco dadas às muitas conexóes de natureza técnica e institucional (POSSAS et al., 1997, p.109-111).

A política regulatória também deve levar em conta o impacto da instabilidade do ambiente econômico sobre a operacionalização dos contratos. É preciso que as relaçóes contratuais possam ser adaptadas e que as agências reguladoras sejam capazes de reagir com flexibilidade e rapidez diante de mudanças imprevistas nas condiçóes de oferta e de demanda. As políticas regulatórias também devem considerar a "presença de externalidades de rede, as quais podem surgir nos setores de infra-estrutura quando estiverem presentes: interfaces tecnológicas que exigem alguma padronização para garantir a compatibilidade entre soluçóes técnicas adotadas pelos diferentes agentes; tecnologias cuja difusão se dá de tal maneira que os ganhos de cada agente com sua adoção dependem da quantidade de outros agentes que também a adotam; e presença de uma base produtiva na qual as empresas operam com fluxos e estoques dentro de um sistema interligado" (POSSAS et al., 1997, p.108).

A regulaçáo é extremamente necessária para garantir a oferta e a qualidade do serviço público, protegendo o usuário dos serviços prestados por concessionárias, mas também para garantir que as obrigaçóes e direitos das concessionárias sejam efetivos. Essa necessidade diminui ao passo que aumenta a concorrência no setor regulado. A regulação se desenvolve, basicamente, por intermédio de normas de comando e controle, que afetam o mercado e as decisóes econômicas das empresas. No entanto, ainda que por meio de normas, é uma função executiva. Em outras palavras, quando existe uma ampla concorrência em determinado setor, o próprio ambiente competitivo gera uma espécie de auto regulação por parte dos ofertantes de serviços e produtos, como no caso da produção de energia e água, onde existem muitos ofertantes. Já no saneamento básico inexiste competição por ser monopólio natural e quase impossível a concorrência por causa do alto custo das redes. No caso do monopólio natural a regulaçáo é de extrema importância para assegurar a estabilidade das regras de operação de mercado.

Porém esta tarefa regulatória é muito complexa, pois o comportamento das concessionárias é de difícil monitoração por parte das agências reguladoras, devido ao fato de somente a concessionária possui as informaçóes de determinados movimentos internos e dos fatores externos que afetam a sua eficiência. No caso de uma região de baixa densidade populacional enfrenta dificuldades de previsão das condiçóes de oferta e demanda muito inferiores às presentes na elaboração de contratos de concessão na telefonia celular, onde a 
rápida evolução tecnológica impóe como regra uma contínua alteração dos níveis de custo e nas características dos serviços prestados.

Para que a regulação seja eficaz é necessária a utilização de vários instrumentos, dentre os quais se destacam "a qualidade dos serviços prestados pelas concessionárias e permissionárias apresenta pontos de tensão que provocam avaliação negativa por grande número de usuários. Os problemas recorrentes das concessionárias e dos usuários são deficiências técnicas, carência de investimentos, políticas e práticas equivocadas de relacionamento entre executores e consumidores, cujos conflitos deságuam no Judiciário. Apenas no Estado do Rio de Janeiro: os Juizados Especiais vêm recebendo, a cada ano, em torno de duzentos mil novos processos, por meio dos quais usuários pedem a condenação de concessionárias à reparação de danos materiais e morais que suportariam, em decorrência de má execução dos serviços" (PEREIRA JUNIOR, 2012, p.122 e 123).

A criação das agências reguladoras fez-se necessária com a desvinculação do Poder Público das responsabilidades de executar obras e serviços públicos. Para que o consumidor dos serviços de interesse público não ficasse desamparado, com a passagem das empresas que antes pertenciam ao setor público para o setor privado, foi preciso haver uma regulação e fiscalizaçáo, até porque o serviço prestado pelo concessionário é uma atividade própria do Estado (ALMEIDA JUNIOR, 2012, p.35).

O ente responsável pela regulação deve sempre atentar-se e tomar conhecimento sobre a atuação de seu regulado para que tenha condiçôes de realizar a fiscalização e o controle de maneira justa. O regulador deve zelar pela imposição de informaçáo, sem a qual não se podem tomar decisóes razoáveis, e na redução de custos de transação. Para tanto, pode adotar "ferramentas regulatórias como proibiçôes, licenças, fixação de padróes técnicos de produção, de padróes de desempenho, disciplinar subsídios, controlar preços e tarifas, impor a provisão de informaçóes, e atribuir, na forma da lei, direitos de propriedade, bem como impor responsabilidades. Todos esses atos podem ser precedidos da edição de normas com os critérios para a sua edição" (SOUTO, 2012, p.52).

A despeito de as especificidades setoriais condicionarem soluçóes distintas, de modo geral a mudança de um modelo de oferta estatal e de regulação pelo financiamento em direção à privatização e a um modelo de regulação baseado em controles explícitos (instituição de agências reguladoras setoriais e adoção do instrumento price cap ${ }^{2}$ ) para a infra -estrutura no Brasil não foi capaz de garantir a expansão dos investimentos e a eficiência

2 Price Cap é uma forma de regulação desenvolvida na Inglaterra, na década de 1980, pelo economista Stephen Littlechild baseia-se na fixação de um preço teto e foi aplicado em todos os "utilities" britânicos privados. Ele contrapóe-se à regulação de taxa de retorno, na qual as empresas determinam uma taxa de retorno sobre o capital, bem como a regulação com base no Custo Marginal - onde o lucro é totalmente regulado. 
do setor e também não foi capaz de garantir a universalização dos serviços. Sucesso foi a quase universalização dos serviços telefonia e de eletricidade para todos brasileiros.

A reforma gerencial enquadrou os serviços públicos de infra-estrutura na condição de atividades de "produção de bens e serviços para o mercado" e definiu a exigência de regulação para esses serviços apenas quando apresentassem a condição de monopólio natural, privilegiando a eficiência e negligenciando a condição de serviço público essencial. Esse fato pode ser comprovado na própria Lei de Concessóes (Lei n.o 8.987/95), que "não menciona uma única vez sequer o conceito de serviço público essencial nem tampouco especifica as condiçóes de necessária eqüidade de acesso aos serviços, remetendo para as legislaçóes que definem os sistemas reguladores setoriais e para os contratos de concessão a definição de "requisitos de pleno atendimento do usuário" (TOLEDO SILVA, 2003, p.17).

O próprio processo de privatização também foi afetado pela ausência de regras claras na regulação do setor de saneamento, como investimentos, inversóes financeiras, metas, critério de tarifas. A própria lei de concessóes propóe que o julgamento dos leilóes seja feito com base na menor tarifa, mas admite a cobrança pela outorga. Os aumentos e reajustes de preços são implementados sem muitos critérios técnicos e muito mais preocupadas em garantir uma taxa mínima de retorno e o equilíbrio financeiro dos contratos. Tanto que essa lei também declarou que a aprovaçáo de ajustes nas tarifas estaria a critério do outorgante da concessão. Conseqüentemente, o cenário de risco afasta o interesse de para qualquer concessionário, quando não existe uma política regulatória bem definida. Todas essas indefiniçóes regulatórias criaram incertezas nos investidores privados e desestimulam os investimentos nas empresas estaduais com concessóes prestes a encerrarem-se. Em suma, a natureza (pública ou privada), a competência (estadual ou municipal) e o tempo de concessão são aspectos regulatórios que devem influir nos investimentos e no desempenho dos serviços de água e esgoto.

$\mathrm{Na}$ tentativa de resolver todas essas questóes, o governo Fernando Henrique Cardoso preparou uma estrutura regulatória com uma política nacional sobre saneamento através do Projeto de Lei 4.147/2001, que estabeleceu autonomia administrativa e financeira para as empresas de saneamento, estabelecendo regras de conduta, princípios de políticas tarifárias e critérios de concessão. Atribuiu a Agência Nacional de Águas (ANA) a coordenação nacional das atividades de regulação dos serviços de saneamento. Entre essas atividades estaria a avaliação do atendimento das normas contidas nesta Lei pelos titulares e prestadores de serviços, como condição para o desenvolvimento de açóes de saneamento básico da União junto a Estados e Municípios. Ainda, estipulou que os Estados tinham o poder de concessão nas áreas metropolitanas, encontrando assim grandes opositores nos patrocinadores dos municípios Em termos de política tarifária o projeto avança na proposiçáo de mecanismos de ajustes de tarifas com o sistema de price cap, no qual deduçóes de 
produtividade são feitas nas variaçôes de ajustes monetários das tarifas e inclui nas tarifas um componente de subsídio cruzado mediante uma contribuição do fundo público de universalizaçáo.

Outra inovação foi à alteração da Lei das Águas (lei 9433/97) com a introdução do instrumento de cobrança pelo uso das águas para orientar o acesso aos nossos rios. Por uma associação equivocada, alguns tendem a considerar que a gestáo de recursos hídricos é a gestão de saneamento, pois se percebe visualmente o impacto dos esgotos nos nossos rios. Entretanto, a gestão de recursos hídricos engloba todos os seus usos e, em muitos casos, outros usos, com menor impacto visual, acabam sendo mais sérios que o da falta de saneamento. Assim, por absurdo, a ANA deveria regular também esses outros usos de água, tais como energia hidroelétrica, irrigação e até navegação. Sem considerar a complexidade das relaçôes assimétricas, teríamos um poder concedente com relaçóes de interesses em alguns concessionários, ou seja, uma trajetória de captura da agência e perda de governança. Enquanto o poder de concessão do acesso aos rios federais é federal, o poder de concessão dos serviços de saneamento é constitucionalmente dividido entre municípios e estados. Logo, a regulação do setor de saneamento teria de ser necessariamente municipal e estadual. Isso não significa que o governo federal deve se ausentar do esforço regulatório do setor, mas que esta participação não legitima a mera transferência do poder regulatório para uma agência federal (ANA).

Aparece também a política tarifária do uso de subsídios cruzados, que à primeira vista são socialmente justos, mas distorce os sinais de preços das tarifas para os consumidores de todas as rendas, pois não são transparentes além de serem limitados na capacidade de pagamento das famílias mais pobres. Alcança-se a universalização por meio de financiamentos de fundo públicos (fundo perdido), pois essa náo se financia por meio de tarifas praticadas. A populaçáo beneficiada seria aquela de menor poder aquisitivo e, portanto, deveria ser tratada no contexto da política social e não de saneamento.

Essa proposta do marco regulatório do saneamento do Governo Fernando Henrique Cardoso (PL 4.147/2001), após muita discussão no Congresso Nacional, foi substituída por outra no Governo Lula, mas mantinha várias controvérsias, entre elas, a que estabelece a titularidade do serviço de saneamento, seja o Estado ou o Município, papel do setor privado, padrão de qualidade, investimentos e tarifas etc. A grande dificuldade da aprovação desse marco regulatório foi quanto à definiçāo da titularidade dos serviços de saneamento, (municipal ou estadual), nos interesses conflitantes das partes interessadas, ou seja, as companhias estaduais versus municípios. De um lado, as companhias estaduais interessadas em manter os serviços sob sua responsabilidade com base na manutenção do subsídio cruzado tal como desenhado no Planasa; de outro, os Municípios interessados em manter a titularidade dos serviços, quando os serviços são de interesse local, para ter a liberdade de explorar esses serviços diretamente ou conceder sua exploração a terceiros, 
ficando com a responsabilidade de regulá-los. Aos Municípios falta de definição quanto à origem dos recursos que financiarão os investimentos necessários para garantir metas razoáveis de cobertura dos serviços.

Desse processo legislativo surge a Lei 11.445/2007, o marco regulatório do saneamento e estabelece os princípios fundamentais para a prestação desses serviços públicos. Desta forma, com a devida regulação dos serviços de saneamento básico entra-se em na esfera de aplicação da lei para assegurar a qualidade dos serviços de água e esgoto. Para adentrar a uma discussão mais profunda sobre saneamento básico, é importante conhecer a lei 11.445/2007. "O consumo humano constitui o uso prioritário da água, pois se relaciona diretamente como o direito à vida. $\mathrm{O}$ abastecimento de água potável insere-se no saneamento básico ou "a solução dos problemas relacionados estritamente como o abastecimento de água e disposição dos esgotos de uma comunidade" (GRANZIERA, 2006, p. 126).

As transformaçóes que vêm ocorrendo no setor de saneamento, com a separaçáo dos sistemas de produção e distribuição de água, de um lado, e de coleta e tratamento de esgoto, de outro, como demonstra no Estado de São Paulo. A Companhia Estadual de Saneamento (Sabesp) produz a água e essa distribui para algumas prefeituras localizadas na Regiáo Metropolitana de São Paulo. Por outro lado, algumas concessóes municipais desses serviços são parciais, como demonstram os exemplos de Ribeirão Preto (esgoto), São Carlos (água), Jundiaí (esgoto), Itu (esgoto), Araçatuba (água).

A despeito da separação dos sistemas de produção e distribuição de água e de coleta e tratamento de esgoto ser uma tendência que vem sendo observada em vários países e também no Brasil, a presença de sunk costs (investimento à fundo perdido) ${ }^{3}$ e o monopólio natural ainda são característicos dessa indústria, este último pelo menos em algumas etapas de sua cadeia produtiva.

\section{Estrutura Regulatória}

A Constituição Federal de 1988 definiu a competência dos serviços de saneamento: o artigo 30, inciso $\mathrm{V}$, reconhece os serviços de saneamento como de competência local; o artigo 21, inciso XX, estabelece como competência da União a instituição de diretrizes para o desenvolvimento urbano, inclusive habitação, saneamento básico e transporte urbano; o artigo 23, inciso IX, define como competência comum da União, dos Estados e

3 É um investimento realizado sem expectativa de retorno de montante investido, realizado geralmente pelo Estado no sentido de melhorar as condiçóes de existência de setores de baixa renda, como a construção de saneamento básico, de moradias populares, obras de infraestrutura como estradas, que estimulam os investimentos privados através da oferta de um produto ou serviço antes inexistente. 
dos Municípios, promover programas de construção de moradia e a melhoria das condiçôes habitacionais e de saneamento básico.

Do penoso e longo processo legislativo é aprovado o marco regulatório (Lei 11.445, de 5 de janeiro de 2007) que especifica as diretrizes nacionais e a política federal de saneamento. A lei estabelece a universalização do acesso; abastecimento de água, esgotamento sanitário, limpeza urbana e manejo dos resíduos sólidos realizados de formas adequadas à saúde pública e à proteção do meio ambiente, integração das infra-estruturas e serviços com a gestão eficiente dos recursos hídricos etc. Também sobre a qualidade da água a ser distribuída para consumo humano. É dever do poder público garantir o abastecimento de água potável à população, que pode ser obtido de rios, reservatórios ou aqüíferos, mediante tratamento nos padróes legalmente estabelecidos de potabilidade, sem qualquer risco de contaminação, conforme a Portaria no 518, de 25-3-04, do Ministério da Saúde.

A observação dessas concepçôes se faz fundamental para que os consumidores desses serviços, que muitas vezes não são prestados como está previsto em lei, e também não tomem conhecimento de seus direitos de exigir melhoria dos serviços públicos. $\mathrm{O}$ art. $26 \mathrm{da}$ Lei no $11.445 / 2007$ assegura a publicidade aos relatórios, estudos, decisóes e instrumentos equivalentes que se refiram à regulação ou à fiscalizaçáo dos serviços, bem como aos direitos e deveres dos usuários e prestadores, a eles podendo ter acesso qualquer do povo.

Por sua vez, a Constituição de 1988 declarou que os serviços públicos, incluídos água e saneamento, deveriam ser fornecidos pela autoridade pública (poder público), diretamente ou através de concessóes, autorizando também as concessóes, em seus artigos 37, caput, e 175. A prestação de serviços públicos pela União, Estados e Municípios pode ser feita diretamente, ou seja, por seus órgáos subordinados de administração direta ou entidades vinculadas de administração indireta, ou mediante delegação contratual a empresas privadas, as chamadas concessionárias ou permissionárias de serviços públicos.

A Constituição e a Lei 8987, de 13 de fevereiro de 1995 (regime de concessão e permissão da prestação do serviço público) são, entretanto, ambíguas quanto à competência no fornecimento dos serviços públicos e de poderes de concessão do setor. Essa Lei de Concessão foi aprovada, desafiando o monopólio das empresas estaduais de saneamento. A lei confirmou que os municípios deveriam ter o poder de fazer concessóes ou entrar em acordos de licenciamento ou, se desejassem, fornecer serviços locais diretamente. Entretanto, a lei abriu a possibilidade para a entrada de companhias regionais. A Lei de Concessão também especificou que os Municípios apenas poderiam renovar o contrato de concessão através de licitaçôes públicas. As empresas estaduais poderiam participar desses leilóes, mas competindo com operadores qualificados do setor privado.

A constituição garantiu aos Municípios o direito de fazer concessôes para os serviços públicos de interesse "local", enquanto reconhecia que os governos federais e estaduais 
deveriam garantir um fornecimento eficiente e bem regulado para os serviços de água e saneamento. Essas duas posiçóes abriram debate sobre como as áreas municipais e metropolitanas atualmente cobertas, na maioria dos casos pelas empresas estaduais, poderiam regular esses serviço.

Fortalece-se a política das concessóes e parcerias. Os contratos de concessão devem buscar a "eficiência econômica, garantindo o serviço ao menor custo para o usuário; evitar o abuso do poder de monopólio, assegurando a menor diferença entre preços e custos, de forma compatível com os níveis desejados de qualidade do serviço; assegurar o serviço universal; assegurar a qualidade do serviço prestado; estabelecer canais para atender a reclamaçôes dos usuários ou consumidores sobre a prestação dos serviços; estimular a inovação (identificar oportunidades de novos serviços, removerem obstáculos e promover políticas de incentivo à inovação); assegurar a padronização tecnológica e a compatibilidade entre equipamentos; e garantir a segurança e proteger o meio ambiente" (PIRES e PICCININI, 1999, p. 403).

Para Jessé Torres Pereira Junior essa diretriz constitucional "resgatou o prestígio da outorga contratual da execução da prestação de serviços públicos a empresas privadas, selecionadas mediante licitação, que havia sido remetida a segundo plano pela multiplicação, a partir de meados do século XX, de empresas públicas ou sociedades de economia mista na administração pública brasileira, criadas por lei ou decreto administrativo, com o fim de executar a prestação desses serviços, quase que relegando a desuso a delegaçáo contratual. (PEREIRA JUNIOR, 2012, p.122).

\section{Breve Histórico do Saneamento}

Até o início do século XIX, era bastante precário o abastecimento de água e inexistente a coleta de esgotos no Brasil. Com o crescimento da população urbana e a ameaça constante de epidemias, os governantes passaram a se preocupar com a questão, levando à implantação desses serviços no final do século XIX. As primeiras redes de distribuição de água e esgoto surgem nas cidades de São Paulo, Rio de Janeiro e Recife, com o governo federal atuando como poder concedente e as empresas estrangeiras encarregando-se da construção dos sistemas e posterior exploração. Nesse modelo, que vigorou até o início dos anos 1930, cabia ao Estado garantir uma rentabilidade mínima na exploração dos serviços. Nesse período, o governo federal delegava a prestação dos serviços públicos a concessionárias estrangeiras, que operavam transportes ferroviários, produçáo e distribuição de energia elétrica, transportes urbanos, telefonia e outras atividades de interesse coletivo, incluindo o abastecimento de água e o esgotamento sanitário nos grandes centros urbanos. Naquela época, as empresas estrangeiras praticamente monopolizavam a tecnologia nessas áreas, bem como os recursos para a realizaçáo dos investimentos. Não 
havia restriçôes à importação de máquinas e equipamentos e a remessa de lucros não onerava o balanço de pagamentos. "As tarifas eram reais, pois inexistia necessidade de subsídios. O governo garantia, inclusive, uma rentabilidade mínima às concessionárias. Dadas as necessidades impostas pelo crescimento urbano, a partir dos anos 1930 o Estado passa a intervir e atuar diretamente nos serviços de saneamento (MARINHO, UFPR, 2012, p.344).

Na década de 1930, mais precisamente no primeiro Governo Vargas, os principais instrumentos regulatórios utilizados foram o "controle de preços básicos (água, eletricidade, gasolina) e a adoção de novos mecanismos de intervenção no sistema de preços com a promulgação do Código de Águas (1934), que conferia ao governo o poder de fixar tarifas de eletricidade que garantissem uma rentabilidade máxima de $10 \%$ sobre o capital investido (GIAMBIAGI, 2000, p.88-89).

O Código de Águas em 1934 foi o início desse processo de intervenção estatal na economia que permitiu a nacionalização e estatização das empresas concessionárias estrangeiras, sendo os serviços geridos pelo Estado e os investimentos financiados com base no orçamento fiscal (SEPURB, Ministério do Planejamento e Orçamento, 1995).

Dois elementos foram de fundamental importância no incremento do saneamento, segundo Toledo Silva: “o Código de Águas (1934) e o Decreto-lei 200/1967. A importância do Código de Águas, por ter definido o domínio público sobre bens e serviços considerados essenciais ao desenvolvimento urbano, estabelecendo, "normas de conduta sobre o conteúdo dos serviços e sua função social, assim como (...) limites à apropriação de lucros por parte dos concessionários" (TOLEDO SILVA, 2003, p. 65). O Decreto-lei 200/67 por ter instituído um modelo regulatório "inovador" que associava o instituto da concessão à regulação pela taxa de retorno, originária do sistema das comissóes reguladoras americanas. $\mathrm{O}$ modelo de regulação pela taxa de retorno instituído no Código consagrou-se em praticamente todos os campos da infra-estrutura e permaneceu como "elemento determinante de toda cultura de regulação e controle dos serviços públicos em rede no Brasil, ao longo de quase 60 anos" (TOLEDO SILVA, 2003, p.2) até o advento da nova Lei de Concessóes 8.987, de 13 de fevereiro de 1995.

Na década de 1960, pela primeira vez, foi instituída uma Política Nacional de Saneamento (Planasa) no Brasil. Essa política consistiu num programa de financiamento com base em recursos públicos (Sistema Financeiro de Saneamento) que foi responsável pela expansão de investimentos fundamentais para garantir a infra-estrutura urbana de apoio ao processo de industrialização da economia brasileira. O Planasa que ficou responsável por todo o planejamento de investimento do setor, assim como as políticas de tarifas, de crédito e outras normas. O Planasa estimulou os Estados a constituírem as Companhias Estaduais de Saneamento com a justificativa de que a abrangência em que seriam organizados os serviços (abrangência regional) permitiria a obtenção de ganhos de escala e a 
viabilização da implementação do subsídio cruzado (tarifa única) como forma de garantir a inclusão dos municípios mais pobres. Incentivou as municipalidades a fazer concessóes de longo prazo para essas empresas em troca de investimentos concedidos pelo Banco Nacional de Habitação (BNH), braço financeiro do Planasa. O BNH, criado em 1964, abrigou o Sistema Financeiro de Saneamento e foi, até meados dos anos 1980, o órgáo responsável pela concessão dos financiamentos de saneamento às Companhias Estaduais e pela regulação das ações de padrões de prestação de serviços e de taxas de retorno apropriadas para os investimentos.

Nesse período houve grande expansão dos serviços de saneamento num momento em que se consolidava uma economia preponderantemente urbana no Brasil. Entretanto, os seus investimentos priorizaram a construção de sistemas de abastecimento de água em detrimento de projetos que reduzissem perdas e melhorassem a eficiência operacional das empresas, resultando num excessivo volume de perdas e ineficiência das empresas ao longo do tempo.

Nas décadas de 1970 e 1980, ainda sob a direção do Planasa, a cobertura de água urbana no Brasil aumentou de 60 \% em 1970 para 86 \% em 1990, e a cobertura do esgoto urbano passou de 22\% em 1970 para 48\% em 1990. Até os anos 1970, os serviços de água e saneamento no Brasil eram fornecidos pelos municípios sob a supervisão da Fundação Nacional de Saúde (Funasa) por sua vez, era supervisionada pelo Ministério da Saúde. A preocupação maior era com a potabilidade da água em detrimento do esgotamento sanitário.

Qual era a forma de funcionamento desse modelo e como ele se tornou inviável? Uma das características do Estado desenvolvimentista foi à instituição de fundos públicos, formados com recursos fiscais e parafiscais, para financiar os investimentos nos setores de infra-estrutura. No caso dos serviços de saneamento, a principal fonte de recursos sempre foi o Fundo de Garantia por Tempo de Serviço (FGTS).

No final dos anos 1980, o sistema Planasa começou a apresentar um baixo desempenho. Os fundos para investimento estavam financeiramente debilitados com a inadimplência e o regime de tarifas não era mais apropriado devido a um ambiente inflacionário. Para agravar o quadro, o governo extinguiu, em 1986, o BNH, incorporando as suas funçôes às da Caixa Econômica Federal. Com a extinção do banco, deu-se início ao desmonte do modelo de gestão e de financiamento estatal instituído para o saneamento no Brasil. Apesar de a Caixa Econômica Federal ter absorvido as funçóes de saneamento do BNH, esta não herdou, conforme aponta Toledo Silva, as "prerrogativas nem a capacidade técnica para exercer a função reguladora que o BNH exercia”, ficando essa funçáo a cargo dos diversos ministérios que se sucederáo no comando do setor, contribuindo para esvaziar a política de saneamento (TOLEDO SILVA, 2003, p.18-19). 
A desativação das linhas de financiamento público à infra-estrutura esvaziou os instrumentos tradicionais de "regulação burocrática pelo crédito", como aconteceu com a extinção do BNH (1985) e dos programas de financiamento do Plano Nacional de Saneamento - Planasa (1989). Com isso, os investimentos em saneamento, que durante toda a década de 1970 chegaram a representar 0,5\% do PIB, caem para 0,2\% do PIB durante a década de 1980, chegando, em alguns anos da década de 1990 (1993-1994), a representar menos que $0,1 \%$ do PIB.

O Planasa também foi fragilizado pelas mudanças institucionais introduzidas pela Constituição Federal de 1988, que estabeleceu de forma confusa de competência desses serviços. Por outro lado, a mudança tributária realizada no âmbito da Constituição de 1988 descentralizou recursos em favor de estados e municípios sem transferir os encargos correspondentes para essas esferas de governo. A Constituição e sua ênfase na descentralização tornaram o esquema Planasa obsoleto e após sua extinção, no final da década de 1980, suas atribuições foram distribuídas a diversos órgãos públicos.

Por outro lado, o processo de redemocratização política, a crise fiscal dos anos 1980, os efeitos da Constituição Federal de 1988 e as reformas administrativas realizadas pelos governos dos presidentes Collor e Itamar provocaram, respectivamente, a distensáo do modelo centralizado Planasa - aplicaçáo de recursos para o saneamento de forma aleatória e fora do Sistema Financeiro de Saneamento - e a desregulamentação do setor.

Em função de problemas de natureza macroeconômica (crise fiscal dos Estados) e microeconômica (busca de uma gestão mais eficiente das empresas), tem-se observado uma tendência geral para o aumento da participação privada no setor. Essa opção tem resultado na redução do papel do Estado como provedor desses serviços e na sua ampliaçáo como regulador da atividade.

Inicia-se no Brasil nos anos 1980 o processo de privatização, mas só se torna prioridade da política econômica no início dos anos 1990 com o Plano Nacional de Desestatização no Governo Fernando Henrique Cardoso (1990). A partir daí, a privatização é inserida dentro da estratégia do governo, que passa a contemplar a promoção das chamadas "reforma de mercado" - abertura comercial, desregulamentação da economia, redução do tamanho do Estado etc. (GIAMBIAGI, 2000, p.378). Assim, durante a década de 1990 foram privatizados os setores de energia elétrica e de telecomunicaçóes e instituído um novo modelo de regulação para esses serviços com base no modelo instituído pela Inglaterra.

A partir daí, os governos da década de 1990, em consonância com as tendências materializada na Reforma Gerencial do Estado Brasileiro, em 1995 e na nova Lei de Concessóes (Lei n.o 8.987/95 e 9.074/95) e mais tarde no governo Lula a lei que cria as parcerias público-privada (PPP) (lei 11.079, de 30/12/04) no âmbito da administraçáo 
pública. Essa reforma enquadrou os serviços públicos de infra-estrutura como atividades de "produção de bens e serviços para o mercado" e exigiu a regulação para esses serviços apenas quando apresentassem a condição de monopólio natural, priorizando a eficiência da indústria e negligenciando a condição de serviço público essencial.

Nos anos seguintes ao Plano Real as empresas tentaram retomar essa capacidade de investimento aliado ao realismo tarifário, mas fracassaram ao manter suas viciadas práticas de gestão associadas a uma ausência de marco regulatório que introduzisse incentivos à eficiência. O quadro de ausência de investimentos, não consegue cobrir todos os custos de provisão dos serviços, quanto mais num quadro de retomada dos investimentos no setor.

As metas de ajuste fiscal dos governos dos ex-presidentes Fernando Henrique Cardoso e Luiz Inácio Lula da Silva dificultam o endividamento do setor público, impedindo a retomada de investimentos no setor em níveis razoáveis. Terceiro, da dificuldade de definir de onde viráo os recursos para garantir o acesso da populaçáo mais pobre aos serviços e, também, como estes recursos serão aplicados: o subsídio cruzado permanecerá no novo modelo? Como ele será implementado? Não seria melhor que o modelo previsse subsídios diretos com recursos de natureza orçamentária - já que poderiam ser contemplados como parte da política do Welfare System (bem estar sanitário), ser mais transparentes e, além disso, não interferir na eficiência das empresas? Em razão desses fatos, a linha de investigação seguida por esta tese procura analisar as características gerais da intervenção do Estado brasileiro na infra-estrutura e nos serviços de saneamento.

Muitos passos estratégicos, gerenciais e operacionais foram dados para que fosse cumprida a nova ordem constitucional, destacam-se dois: leis específicas foram editadas, para disciplinar o regime de concessóes e permissôes; autarquias especiais foram criadas, para regular cada segmento da prestação dos serviços públicos (águas e esgoto, energia elétrica, telecomunicaçóes, transportes e combustíveis) (PEREIRA JUNIOR, 2012).

O Governo Lula propôs um novo marco regulatório e uma nova política de saneamento enfrentou inúmeras críticas, especialmente por parte das companhias estaduais, relacionadas ao fato de o projeto reforçar a titularidade municipal dos serviços em qualquer caso e, além disso, náo definir de forma clara a origem e o montante de recursos que comporão os fundos de universalização e qual o papel esperado das parcerias público-privadas, entre outras.

Surge em 2013, o último Plano Nacional de Saneamento Básico (Plansab) um ambicioso plano de investimentos de mais de 500 bilhóes de reais para os próximos vinte anos (2014-2033), num esforço governamental e em parceiras público-privada para enfrentar e resolver o problema do saneamento no Brasil. Esse é o primeiro plano de saneamento construído de forma democrática do governo com a sociedade civil, os agentes públicos e privados que atuam no setor. O BNDES oferece linhas próprias de financiamento no 
vasto universo do saneamento básico, desde a captação de águas, redes de distribuição, coleta e tratamento e de esgoto e de lixo urbano. $\mathrm{O}$ anuncio de corte de investimento (2015) decorrente com a crise fiscal do Estado condena o saneamento a uma paralisia que ameaça esse plano.

\section{Características do Setor de Saneamento no Brasil}

O setor de saneamento é caracterizado por baixo dinamismo tecnológico e apresentam-se com pequenas variaçóes na oferta de serviços (água e esgoto), quando comparada à de outros setores de infra-estrutura, como telecomunicaçóes. Ao mesmo tempo é caracterizado por uma grande heterogeneidade quanto ao tamanho, número de prestadores envolvidos, forma de gestão e de desempenho (eficiência) e de investimentos (MARINHO, UFPR, 2012, p.344).

Para iniciar as características dos serviços de saneamento básico no Brasil, é interessante demonstrar alguns dados do SNIS 2012 (Ministério das Cidades): I) Atendimento em água potável: quando consideradas as áreas urbanas e rurais do País, a distribuição de água atinge $82,4 \%$ da população; II) $\mathrm{O}$ atendimento em coleta de esgotos: chega a $48,1 \%$ da população brasileira. Do esgoto gerado, apenas $37,5 \%$ recebe algum tipo de tratamento; III) Crescimento das ligaçóes: entre 2010 e 2011, houve um crescimento de 1,4 milhóes de ramais de água e 1,3 milhóes na rede de esgotos no País, crescimentos relevantes quando se trata de ampliação de sistemas complexos nas cidades brasileiras; IV) O consumo de água por habitante no Brasil: foi de 162,6 litros por habitante ao dia, um pequeno incremento de 2,3\% em 2011 com relação a 2010. A região com menor consumo é a Nordeste, com 120,6 litros por habitante por dia; já a região com maior consumo é a região Sudeste, com 189,7 litros por habitante por dia; V) Perda de água: as médias de perdas de água na distribuição alcançaram 38,8\%, mantendo-se no mesmo patamar de 2010; VI) Receitas totais geradas pelos serviços de água e esgotos: alcançaram os $\mathrm{R} \$$ 76,0 bilhôes (2011); VII) Investimentos: movimentação financeira de $\mathrm{R} \$$ 76,0 bilhôes no ano de 2011, referente a investimentos que totalizaram $\mathrm{R} \$ 8,4$ bilhóes, mais receitas operacionais de $\mathrm{R}$ \$ 35,0 bilhóes e despesas de $\mathrm{R} \$ 32,6$ bilhóes; VIII) Posto de trabalho: em 2011, o setor de saneamento gerou 642,9 mil empregos diretos e indiretos e de efeito renda em todo o país. Desses, 198,9 mil nas atividades diretas de prestação dos serviços e 444,0 mil gerados pelos investimentos.

O déficit de atendimento dos serviços de saneamento no Brasil, apresentando forte desigualdade de atendimento por serviço prestado (água e esgoto), entre as regióes (sul e sudeste em detrimento de nordeste, norte e centro-oeste), e por origem de domicílio atendido (urbano e rural), bem como uma expressiva iniqüidade social. De acordo com essa hipótese, existiria uma relação não linear, no formato de um "U invertido" 
entre indicadores de degradação e o desenvolvimento econômico, ou seja, nos primeiros estágios do desenvolvimento, a degradação aumentaria, mas passaria a diminuir em estágios mais avançados. Tal hipótese justifica a afirmação de Beckerman (1992) de que o desenvolvimento econômico possui impactos iniciais negativos sobre o meio ambiente, mas que, ao longo do tempo, seria a melhor forma de gerar uma maior preservação ${ }^{4}$.

Dados da Organização Mundial da Saúde (OMS) no ano de 2004, em cada R \$ 1,00 investido em saneamento gera economia de $\mathrm{R} \$ 4,00$ na área da saúde. Isso demonstra a extrema importância desse serviço para a saúde da população, sendo que $88 \%$ das mortes por diarréias no mundo são causadas pelo saneamento inadequado (IBGE, 2012).

De acordo com a Pesquisa Nacional por Amostra de Domicílios (PNAD 2012): I) Dos 62,8 milhóes de domicílios, quase 27 milhóes de residências $(42,9 \%)$ ainda não têm rede coletora de esgoto; II) $\mathrm{O}$ número de domicílios beneficiados por rede coletora de esgoto aumentou de 54,9\% em 2011, para 57,1\% em 2012; III) O maior crescimento regional ocorreu no Sul, onde o avanço foi de 35,7\% em 2011 para 42,3\% em 2012. A região Norte se manteve estável em relação a 2011 com 13\% de domicílios com acesso a rede coletora de esgoto. O Sudeste ainda é a região com melhor cobertura de rede de esgoto, 84,1\% dos domicílios tem o serviço; IV) A cobertura de redes de água em todo o País aumentou de 84,6\%, em 2011 para 85,4\%, em 2012; V) O acesso a coleta de lixo em todo o País permaneceu em 88,8\% entre os anos de 2011 e 2012; VI). A utilização de fossa rudimentar permaneceu em 16,6 \% entre os anos de 2011 e 2012 em todo o País.

Uma característica que dificulta a verificação das condiçóes de manutenção e operação é a localização da infra-estrutura, que se encontra enterrada. Isso gera uma necessidade maior de fiscalização e de informaçáo para os reguladores. Existe ainda a assimetria de informaçóes, que faz com que o regulador focalize sua atuação nas condutas mais facilmente observáveis do regulado, como a qualidade da água distribuída e a pressão da mesma na rede. Isso faz com que questóes mais importantes sejam colocadas em segundo plano, como a verificação das tarifas e custos, pois para a regulação destas é necessário à disponibilização de informaçóes por parte dos prestadores de serviços. (GALVÃO JUNIOR e PAGANINI, 2009, p.159)

Outro fator que dificulta a regulação neste setor é fato de serem efetuados grandes investimentos, isso pode levar a um comportamento oportunista por parte dos reguladores, como mudanças de regras tarifárias após a construção de obras e instalaçôes

4 O presente estudo avaliou a existência de uma Curva Ambiental de Kuznets (CAK) para o caso dos déficits municipais de acesso a serviços de saneamento ambiental, que podem ser considerados como medidas indiretas de degradação ambiental. SAIANI, Carlos César Santejo at ali. Déficit de acesso a serviços de saneamento ambiental: evidências de uma Curva Ambiental de Kuznets para o caso dos municípios brasileiros? Disponível http://www.scielo.br/pdf/ecos/v22n3/08.pdf 08/03/2015 
operacionais. Isso torna necessário que o marco regulatório ofereça garantias e estabilidade de regras claras para os investidores (GALVÃO JUNIOR e PAGANINI, 2009, p. 406).

As características do setor de água e esgoto apresentadas no quadro abaixo possibilitam analisar várias dimensóes dessa prestação de serviços e justificam a extrema necessidade de haver a regulação do setor.

\section{Características do setor de saneamento e suas repercussões}

\begin{tabular}{|c|c|c|}
\hline \multicolumn{2}{|c|}{ Caracteristicas } & Repercussões \\
\hline 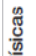 & $\begin{array}{l}\text { Qualidade dos produtos de compl- } \\
\text { exa verficaçáo pelo usuário }\end{array}$ & $\begin{array}{l}\text { Necessidade de estrutura adequada para monitoramento da qualidade de produtos e serviços oferta- } \\
\text { dos pelas concessionárias }\end{array}$ \\
\hline & $\begin{array}{l}\text { Redes integradas em aglomerados } \\
\text { urbanos }\end{array}$ & $\begin{array}{l}\text { Envolvimento de mais de um ente federado na gestáo dos serviços; } \\
\text { Expansâo da intraestrutura associada ao planejamento urbano }\end{array}$ \\
\hline & $\begin{array}{l}\text { Essencialidade no uso e consumo } \\
\text { dos produtos (água e esgoto) }\end{array}$ & $\begin{array}{l}\text { Atendimento independe da capacidade de pagamento do usuário: } \\
\text { Geraçáo de externalidades positivas e negativas para a saúde pública, meio ambiente, recursos hídri- } \\
\text { cos, entre outros }\end{array}$ \\
\hline है & Assimetria de informaçَ̄es & $\begin{array}{l}\text { Demais atores do setcr dəpendəm da informaçăo técnica e econômico-fnanceira disponibilizada pelas } \\
\text { concessionárias }\end{array}$ \\
\hline & Demanda inelástica & Possibilidade de extraçăo de rendas significativas pelo prestador de serviços (monopólio) \\
\hline & Economias de escala & Viabilidade da prestaçáo dos serviços por uma única empresa (monopólio) \\
\hline & Economias de escopo & $\begin{array}{l}\text { Custos comuns na oporaçáo do sorviços do água o osgoto o tratamonto do osgotos, tornando mais } \\
\text { viável a prestaçáo dos serviços por uma única empresa (monopólio) }\end{array}$ \\
\hline
\end{tabular}

Fonte: Alceu de Castro Galvão Junior e Wanderlei da Silva Paganini

Enfim, essas características apresentam situaçóes perigosas existentes no setor, como poder de monopólio e assimetria de informação, o que justifica a regulação do setor. Além disso, a regulação é necessária para que sejam realizadas práticas eficientes de gestão, expansão do produto, redução de tarifas, bem estar do consumidor pela qualidade dos serviços e universalização.

A pesquisadora em saneamento Marina Mello identificou alguns desses mesmos problemas nos contratos de quatro concessóes plenas realizadas entre 1995/1998 (Águas de Limeira, Águas de Petrópolis, Pró- Lagos e Águas de Jaturnaíba). Nos em três casos, o leilão se deu com base na cobrança de outorga (Águas de Petrópolis, Pró-Lagos e Águas de Jaturnaíba) e em um caso (Águas de Limeira) com base na menor Tarifa Referencial de Água (TRA), ou seja, sem o pagamento dos direitos de outorga. Na maior parte dos casos, o esgoto continua sendo cobrado com base numa proporção da tarifa de água. 
As metas físicas dos contratos são relativamente modestas, em que pese o período da concessão ser de 30 anos, não prevendo a cobertura total dos serviços, principalmente de coleta e tratamento de esgotos e não define quem deve ser atendido prioritariamente. Registra o descuido com relação ao sistema de preços de forma a aproximá-lo de critérios de eficiência e de equidade e apenas algumas iniciativas tímidas para adequar preços a custos de atendimento mediante diferenciação de tarifa de esgoto, principalmente no que diz respeito a consumidores industriais. Os padróes de qualidade inadequadamente definidos e não há determinação de avaliação de desempenho dos concessionários privados (MELLO, 2001, p.20-21).

\section{Conclusões}

A essencialidade dos serviços de saneamento básico para a população atribui-se com saúde pública preventiva fez a sua regulação, com a finalidade de fiscalizar, controlar e corrigir possíveis falhas no setor. Assim a regulação do saneamento no Brasil surgiu justamente quando os serviços passaram a ser prestados por empresas concessionárias privadas, pois até 1995, quase todas concessionarias eram publicas ou semi-públicas.

Em regra houve uma melhora do setor de saneamento à populaçáo brasileira, mas quanto à prestação desses serviços esse vem se dando de forma desigual, seja por tipo de serviço prestado, por região ou entre os setores sociais e faixa de renda. Quanto à desigualdade regional de renda, a solução para o alcance de metas de universalização desses serviços depende da garantia de financiamento público, que compreenda aporte de recursos para financiar os investimentos em regióes e/ou municípios carentes e a implementação de uma política de subsídio.

A insistência regulatória está na definição clara das regras e nos contratos de concessão, taxa mínima de retorno e equilíbrio econômico-financeiro, definindo metas e resultados, metas de expansão compatíveis com a universalização dos serviços e regimes tarifários relacionados à eficiência produtiva e tecnológica e o repasse dos ganhos de produtividade aos usuários em benefícios as empresas envolvidas e a qualidade de vida.

A Pesquisa Nacional por Amostra de Domicílio (PNAD 2012) mostra que o Sudeste ainda é a regiáo com melhor cobertura de rede de esgoto, com 84,1\% dos domicílios. De acordo com os relatórios técnicos, pode-se observar que houve avanços no abastecimento e tratamento de água e coleta e tratamento de esgoto em todo o Brasil, contudo desigualmente em cada regiáo. Registram-se resultados positivos em vários aspectos, como o ganho de lucro das empresas, à modicidade tarifária de forma geral e a melhoria da saúde pública.

O problema grave situa-se pontualmente em relação à captação e o tratamento do esgoto sanitário. Há desigualdade na distribuição dos serviços de saneamento no município, 
seja por região, bairro, renda etc. Os serviços mais precários estão nos bairros mais pobres em desacordo com o ideal de saneamento básico previsto na lei 11.445/2007. Muitas vezes, apesar de existir estação de tratamento de esgoto não se oferece serviço de coleta e tratamento de esgoto em todo território das cidades. Parte desse esgoto coletado é jogada, sem condições sanitárias, perto de corpos de água (rio, lagoa e mar). A cobertura da rede de esgoto na área rural é menor, porém tem menores conseqüências devido ao alto número de fossas sépticas, que têm capacidade de eliminar de forma segura o esgoto em áreas de baixa densidade populacional.

Por fim, conclui-se que houve avanços consideráveis no sistema de saneamento, mas há falha de métodos na regulação quanto à execução dos contratos com as concessionárias, principalmente na prestação do serviço de esgoto.

\section{Referências}

ALMEIDA JUNIOR, João Theotonio Mendes. A Regulação da Água: O Papel da Agência Nacional de Águas. Rio de Janeiro: Lúmen Júris, 2012.

ARAGÃO, Alexandre Santos de. Agências reguladoras e a Evolução do Direito Administrativo Econômico. Rio de Janeiro: Forense, 2009.

BRASIL. Ministério da Administração Federal e da Reforma do Estado. Plano diretor da reforma do aparelho do Estado. Brasília: 1995. http://www.bresserpereira.org.br/ documents/mare/planodiretor/planodiretor.pdf acesso em 10 de dezembro 2014.

BRITTO, A.L.N.P. A Regulação dos serviços de saneamento no Brasil: perspectiva histórica, contexto atual e novas exigências de uma regulação pública. In: ENCONTRO NACIONAL DA ANPUR. 9, 2001. Rio de Janeiro: Anais ANPUR, 2001, p. 10801093.

BUZANELLO, José Carlos. Sobre o Estatuto da Regulação no Brasil. In: Maria Teresinha Pereira Silva e Maurício Zanotelli. (Org.). Direito e Administração Pública. Curitiba: Juruá, 2011, v. 1, p. 181-198.

CONFORTO, G. A regulação e a titularidade dos serviços de abastecimento de água e esgotamento sanitário no Brasil. Revista de Administração Pública, Rio de Janeiro: v. 34, n. 5, p. 165-80, set./out. 2000.

DALLARI, A.A.; Consórcios Públicos e Saneamento Básico. Revista de Direito da Procuradoria Geral. Rio de Janeiro: Edição Especial, 2012.

FARINA, E.M.M.Q.; AZEVEDO, P.F.; PICCHETTI, P. A reestruturação dos setores de infra-estrutura e a definição dos marcos regulatórios: princípios gerais, características e problemas. In: Infra-estrutura: perspectivas de reorganização, regulação. Brasília: Ipea, 1997. v. 1, p. 43-80. 
FREITAS, J. Regulação de Estado, Sustentabilidade e o direito fundamental à boa Administração Pública. Revista de Direito da Procuradoria Geral. Rio de Janeiro: Edição Especial, 2012.

FREITAS, M.B.; FREITAS, C. A. Vigilância da Qualidade da Água para consumo humano: desafios e perspectivas para o sistema único de saúde. Rio de Janeiro: Fiocruz, 2005.

GALVÃO JUNIOR, A.C.; PAGANINI, W.S. Aspectos conceituais da regulação dos serviços de água e esgoto no Brasil. São Paulo: Marco 2009.

GALVÃO JUNIOR, A.C.; XIMENES, M.A.F. Regulação: Normatização da Prestação dos Serviços de Água e Esgoto. Fortaleza: Pouchain Ramos, 2008.

GIAMBIAGI, Fábio; MOREIRA, Maurício Mesquita (Orgs.). A economia brasileira nos anos 90. Rio de Janeiro: BNDES, 2000, p.88-89.

GRANZIERA, Maria Luiza Machado. Direito de Águas. Disciplina Jurídica das Águas. $3^{\mathrm{a}}$ ed. São Paulo: Atlas, 2006.

INSTITUTO TRATA BRASIL. Situação do Saneamento no Brasil. Trata Brasil. Disponível em: <www.tratabrasil.org.br>. Acesso em: 25 nov. 2014.

MARINHO, Maria Japiassú. Regulação dos serviços de saneamento no brasil. Tese de doutorado em economia - UFPR. Disponível http://www.economia.ufpr.br/teses\%20 doutorado/14\%20\%20maria\%20do\%20socorro\%20japiassu\%20marinho.pdf Acesso em: 7 março 2015.

MANNHEIMER, S.N. Regulação de Serviços Públicos: a ASEP-RJ. Revista de Direito da Procuradoria Geral. Rio de Janeiro: vol. 50, 1997.

MOREIRA, E.B. Concessão de Serviço Público: breves notas sobre a atividade empresarial concessionária. Revista de Direito da Procuradoria Geral. Rio de Janeiro: Edição Especial, 2012.

MELLO, Marina Figueira de. Privatização do setor de saneamento no Brasil: quatro experiências e muitas liçóes. Rio de Janeiro: Departamento de Economia da PUC-RIO, set. 2001. (Texto para Discussão n. 447).

NEVES, S.B.; Direito econômico e sua nova lógica para o direito administrativo: as agências reguladoras. Revista de Direito da Procuradoria Geral. Rio de Janeiro: vol.64, 2007.

PENA, D.S.; ABICALIL, M.T. Saneamento: os desafios do setor e a política de saneamento. In: Infra-estrutura: perspectivas de reorganização do saneamento. Brasília: Ipea, 1999, p. 107-137.

PEREIRA JUNIOR, J.T. Relação entre Concessionárias de Serviços Públicos e seus Usuários: do regular exercício ao abuso do direito. Revista de Direito da Procuradoria Geral. Rio de Janeiro: Edição Especial, 2012. 
PIETRO, Maria Sylvia Zanella Di. 500 Anos de Direito Administrativo brasileiro. Revista Brasileira de Direito Administrativo - RBDA. Ano 1, n. 1, abr/jun. 2003. Belo Horizonte: Forum, 2003. p. 181-210.

PIRES, J.C.L.; PICCININI, M. S. Regulaçâo dos Setores de Infra-Estrutura no Brasil. Rio de Janeiro: BNDES, 1999.

PIZAIA, Márcia Gonçalves et al. A Política Regulatória do Uso da Água: estudo de caso para o Estado do Paraná. Rio de Janeiro: FGV: Cadernos EBAPE.BR, volume II, no 3, dezembro 2004.

POSSAS, Mario Luiz et al. Regulação da concorrência nos setores de infra-estrutura no Brasil: elementos para um quadro conceitual. In: REZENDE, Fernando; PAULA, Tomás Bruginski de (Coords.). Infra-estrutura: perspectivas de reorganização. Brasília: IPEA, 1997, p. 109-111.

SAIANI, Carlos César Santejo at al. Déficit de acesso a serviços de saneamento ambiental: evidências de uma Curva Ambiental de Kuznets para o caso dos municipios brasileiros? Disponível http://www.scielo.br/pdf/ecos/v22n3/08.pdf acesso 08/03/2015.

SOUTO, M,J,V.; Audiência Pública e Regulação. Revista de Direito da Procuradoria Geral. Rio de Janeiro: Edição Especial, 2012.

SUTTON, R.I.; STAW, B. O que Não é Teoria. Revista de Administração de Empresas. São Paulo: ERA, v. 43, n.3, jul-set, 2003.

TOLEDO SILVA, Ricardo. Público e privado na oferta de infra-estrutura urbana no Brasil. In: Dossiê: serviços urbanos, cidade e cidadania. Disponível em www.usp.br/fau/ docentes/deptecnologia/r_toledo/.../GEDIMRTS.doc, em 21 maio 2014.

VARGAS, M.C.; LIMA, R.S. Concessóes Privadas de Saneamento no Brasil: bom negócio para quem? São Paulo: Ambiente \& Sociedade - Vol. VII no. 2 jul./dez. 2004. 